\title{
Smoking behavior and social contexts associated with smoking among dual-smoker couples
}

\author{
Seung Hee Choi PhD RN, Assistant Professor ${ }^{1}$ (D) | Jiying Ling PhD, Assistant Professor ${ }^{2}$ | \\ Devon Noonan PhD, Associate Professor ${ }^{3}$ | Woojong Kim PhD, Assistant Professor ${ }^{4}$
}

${ }^{1}$ College of Nursing, Wayne State University, Detroit, MI, USA

${ }^{2}$ College of Nursing, Michigan State University, East Lansing, MI, USA

${ }^{3}$ Duke University School of Nursing, Durham, NC, USA

${ }^{4}$ Department of Social Work, University of Michigan, Flint, MI, USA

Correspondence Seung Hee Choi, College of Nursing, Wayne State University, 5557 Cass Ave \#350, Detroit, MI 48202, USA.

Email: hc0054@wayne.edu

\begin{abstract}
Objectives: To examine smoking behavior and social contexts related to smoking among dual-smoker couples.

Design: Cross-sectional online survey study.

Sample: A convenience sample of 183 dual-smoker couples.

Measurements: Investigator-developed survey on smoking and related social contexts.

Results: Participants smoked 16.0 cigarettes daily for 14.2 years; $48.4 \%$ shared more than half of their smoking time with their spouse. More than half made quit attempts in the past year individually $(M=5.3)$ and jointly $(M=2.5)$. Couples sharing more smoking time were more likely to be motivated to quit $(p=.002)$, make quit attempts $(p<.0001)$, and be interested in cessation interventions ( $p=.002)$; but less likely to implement home smoking bans $(p<.001)$. Among those who reported quit attempts, $41 \%$ quit by themselves and $15.3 \%$ sought professional assistance. Most common reasons for relapse were chronic stress and crisis, $63.6 \%$, however, were interested in smoking cessation services, preferably technology-based interventions.

Conclusions: We found smoking interdependence within dual-smoker couples. Despite high levels of motivation to quit, most did not utilize professional help, leading to low successful quit rates. Technology-based smoking cessation interventions incorporating spousal support and addressing stress/crisis may best assist dualsmoker couples.
\end{abstract}

\section{KEYWORDS}

dual-smoker couples, smoking, tobacco

\section{1 | INTRODUCTION}

Over the past 50 years, smoking prevalence in the United States (US) has dropped from $42 \%$ to $15 \%$ (CDC, n.d.). Interestingly, the number of clusters of smokers connected in social contexts, such as family members, co-workers and friends has decreased, yet the size of clusters (number of smokers within the clusters) has remained relatively unchanged (Christakis \& Fowler, 2008). Such a pattern suggests that a group of smokers-dual-smoker couples-quit together, and one quitter can motivate the others to quit (Boyd, Ranby, MacKillop, \& Lipkus, 2016). The most fundamental group of smokers connected in social contexts is married couples, dual-smoker couples.

Spousal concordance in smoking behavior has been observed in large-scale studies (Falba \& Sindelar, 2008; Jackson, Steptoe, \& Wardle, 2015; Venters, Jacobs, Luepker, Maiman, \& Gillum, 1984). In the US, although there are wide variations in previous studies, 
$23 \%-76 \%$ of current smokers are partnered with someone who smokes (dual-smoker couples) (Choi, Pohl, Terrell, Redman, \& Duffy, 2013; Kendrick et al., 1995; Rohrbaugh, Shoham, Skoyen, Jensen, \& Mehl, 2012; Severson, Andrews, Lichtenstein, Wall, \& Zoref, 1995; Tidey \& Rohsenow, 2009). While living with a smoking spouse is associated with becoming a smoker or relapsing after quit attempts, living with a non-smoker is also associated with quitting and making more quit attempts (Falba \& Sindelar, 2008; Jackson et al., 2015; Venters et al., 1984).

Dual-smoker couples are at a higher risk for smoking-related morbidity and mortality due to exposures related to both of the members' smoking (Lipkus, Ranby, Lewis, \& Toll, 2013). Nonetheless, they reported fewer quit attempts, lower cessation rates, and higher relapse rates than single-smoker couples (one member smokes and one does not) (Christakis \& Fowler, 2008; Dollar, Homish, Kozlowski, \& Leonard, 2009; Hawkins, Hollingworth, \& Campbell, 2010; Lee \& Kahende, 2007; Manchón Walsh et al., 2007). Unsuccessful outcomes may be related to the social contexts of dual-smoker couples, such as home smoking policies and lack of spousal support for smoking cessation (Gilpin, White, Farkas, \& Pierce, 1999; Homish \& Leonard, 2005). Home smoking bans are considered social pressure on smoking. A complete home smoking ban is associated with smoking reduction and successful cessation (Gilpin et al., 1999), yet home smoking policies of dual-smokers have not been investigated.

Moreover, dual-smoker couples may mutually support both of their smoking, thus they consider smoking beneficial for their relationship and view cessation as a threat (Rohrbaugh et al., 2001), which may lead to low levels of spousal support for smoking cessation (vanDellen, Boyd, Ranby, MacKillop, \& Lipkus, 2015). Such social contexts can make smoking cessation more challenging and difficult for dual-smoker couples, yet smoking behavior and social contexts associated with smoking in dual-smoking couples are poorly studied in the literature. Most of the previous studies focused on pregnant and/or postpartum women (Homish, Eiden, Leonard, \& Kozlowski, 2012; Park, Chang, Quinn, Ross, \& Rigotti, 2009; Severson et al., 1995), newly married couples (Dollar et al., 2009; Homish \& Leonard, 2005), or health compromised patients and their spouses (Rohrbaugh et al., 2012, 2001; Shoham, Rohrbaugh, Trost, \& Muramoto, 2006), limiting generalizability. A better understanding of such information would provide a foundation to develop interventions tailored to dual-smoker couples. Therefore, the aim of this study was to examine smoking behavior and social contexts related to smoking among dual-smoker couples from a sample of community dwelling adults.

\section{2 | METHODS}

\section{1 | Design}

This was a cross-sectional online survey study. From a convenience sample of 183 dual-smoker couples, the survey questions collected data on participant's and their spouse's smoking behaviors, quit attempts, smoking-related social contexts, comorbidities, and demographics. Dual-smoker couples were defined as married and cohabiting couples where both members currently smoke or quit smoking within the last month.

\subsection{Sample}

A convenience sample of dual-smoker couples were recruited from online and offline (Dillman, Smyth, \& Christian, 2014). The inclusion criteria were those who (a) were at least 18 years of age, (b) currently smoked cigarettes or quit smoking within the past month, (c) had a spouse who currently smoked cigarettes or quit smoking within the past month, (d) were married and cohabiting with a spouse, and (e) lived in the US. There were 374 participants in the original study. Of these, 191 responses (51.1\%) were excluded from the final analysis (13 incomplete surveys, 32 ineligible, 146 fraudulent data entry), resulting in the final sample of 183 (Choi, Mitchell, \& Lipkus, 2017).

\section{3 | Procedure}

To recruit dual-smoker couples, study flyers, containing information about the study title, purpose, inclusion criteria and the link to the study consent form, were posted online via Facebook and Craigslist. Facebook ads targeted those who lived in the US, were older than 18 years of age, spoke English, and were interested in either family, parenting, marriage, and/or dating. Craigslist advertisements were posted 5 days per week in the volunteer opportunities section in major cities, including the top 10 US cities with the highest prevalence of smoking (Gallup n.d.). Recruitment occurred from July 2015 to December 2016. Study flyers were also distributed offline and posted in public places, such as coffee shops and public libraries.

As on the flyers and study advertisements, participants were instructed to provide consent online prior to beginning the survey. Once participants completed the survey, they were automatically entered into a raffle to win a $\$ 10$ gift card. The appropriate Institutional Review Board (IRB) designated this study exempt.

\section{4 | Measures}

Smoking behaviors assessed included current smoking status, years of smoking, daily cigarette consumption, barriers/motivations to quit, use of other tobacco products (cigars, pipes, cigarillos, and snuff), and previous quit attempts. Current smokers were defined as those who currently smoked or quit smoking within the last month (Prochaska, Velicer, Fava, Rossi, \& Tsoh, 2001). Additionally, nicotine dependence was assessed using the reliable and valid Fagerstrom Test of Nicotine Dependence (FTND). The scores range 0-10, with higher scores indicating a greater intensity of nicotine dependence (Heatherton, Kozlowski, Frecker, \& Fagerstrom, 1991). Scores $\geq 6$ indicate high levels of nicotine dependence (Heatherton et al., 1991). Social contexts related to smoking included spouse's smoking 
behaviors (current smoking status, daily cigarette consumption), joint quit attempts, and home-smoking bans.

Demographic information included age, sex, race, marital status, educational level, employment status, and occupation. Self-reported medical comorbidities (cancer, lung disease, heart disease, high blood pressure, stroke, psychiatric problems, diabetes, and arthritis) were also collected (Mukerji et al., 2007).

\section{5 | Statistical analysis}

Descriptive statistics (means, medians, ranges, and frequencies) were conducted for all variables. Means/medians, standard deviations, and ranges were assessed for interval-level variables, and frequencies and percentages were evaluated for nominal- and ordinal-level variables. To examine associations between smoking behavior and social contexts, chi-square tests were conducted. Power analysis was conducted to evaluate adequacy of sample size in chisquare tests. All observed power values of all chi-square tests were higher than 0.80 (Cohen, 1988). All analyses were performed using the SAS 9.4 statistical program.

\section{3 | RESULTS}

\section{1 | Demographic characteristics}

Table 1 shows the demographic characteristics of the sample. The mean age was 34.07 years old, ranging 19-64. About half of the sample was female (56.91\%) and the majority was White (78.99\%). The mean year of marriage was 7.33 years. Over a quarter of participants had a high school or less education (27.83\%). The majority were employed (70.83\%), and, surprisingly, about half of the sample reported one or more comorbidities (45.76\%).

\subsection{Smoking behavior}

On average, participants began smoking at 18.49 years of age, had smoked for 14.24 years, and smoked 16.14 cigarettes daily. Over one-third of the sample had scores of six or higher on the FTND, indicating high nicotine dependence (Table 1; Fagerström et al., 1996).

About $65 \%$ were motivated to quit within either the next month (27.85\%) or 6 months (36.71\%). While $46.20 \%$ made individual quit attempts for at least $24 \mathrm{hr}$ in the past year, with an average of 5.27 times, only $33.30 \%$ made joint quit attempts with their spouse. Unfortunately, the most common method used in quit attempts was "quit on own" (40.98\%) and fewer smokers sought assistance, such as nicotine replacement therapy (NRT) (15.30\%) and the buddy system (13.66\%). Dual-smoker couples identified the following reasons to resume smoking after quit attempts: chronic stress (25.14\%), crisis in their life (19.13\%), social/party situations (18.03\%), and withdrawal symptoms (18.03\%). Besides cigarettes, $23.10 \%$ used other tobacco products, such as cigars (12.02\%), cigarillos (9.29\%), and pipes (8.20\%).

\subsection{Social contexts associated with smoking}

Table 2 describes smoking-related social contexts, including spousal smoking behavior. The spouses' mean cigarette consumption was $16.88 /$ day, which is very similar to the participants' consumption. Over half of participants spent more than $50 \%$ of smoking time with their spouse. Smoking bans at home were not common, only 7.19\% never allowed smoking, and 56.83\% always allowed smoking at home.

One-third of participants reported that they made joint quit attempts in the past year, albeit the range was wide with the mean of 1.48 . Health concerns (41.86\%) followed by cost/money $(16.28 \%)$ were the leading motivations for joint attempts. The majority of the participants (63.58\%) expressed interest in smoking cessation services tailored to dual-smoker couples. For successful quit attempts, $42.22 \%$ indicated they would need a great deal of spousal support for smoking cessation; $49.30 \%$ reported they would be likely/extremely likely to be successful if their spouse helped them quit. Preferred smoking cessation interventions were web-based smoking cessation interventions (24.04\%), followed by pharmacotherapy (22.95\%), mobile interventions (19.13\%), and workbook/video (19.13\%).

To examine the associations of these social contexts with smoking among dual-smoker couples, further analyses were conducted comparing those who smoked with their spouse $<50 \%$ of their smoking time with those who smoked with spouse $\geq 50 \%$ of their smoking time (Table 3). Compared to couples sharing less smoking time, couples sharing more smoking time were more likely to be motivated to quit ( $p=.002$ ), made more individual and joint quit attempts $(p<.0001)$, and be more interested in smoking cessation interventions ( $p=.002$ ), but implemented fewer smoking bans at home $(p<.001)$. Moreover, couples sharing more smoking time expressed more needs of spousal support for smoking cessation $(p=.002)$ and expected more success if their spouse helped $(p=.015)$.

\section{4 | DISCUSSION}

This study examined detailed smoking behavior and social contexts associated with smoking among dual-smoker couples. Our study findings support close interdependence and spousal concordance of smoking patterns (Falba \& Sindelar, 2008; Jackson et al., 2015; Venters et al., 1984). Dual-smoker couples reported similar daily cigarette consumptions (16.14/day among participants vs. 16.88/day among spouses) and more than half of the participants shared more than half of their smoking time with their spouses.

Some smoking characteristics of the participants should be noted. Participants of this study smoked 16.14 cigarettes per day and started smoking at 18.49 years of age in average. While 
TABLE 1 Characteristics of the sample

\begin{tabular}{|c|c|c|}
\hline & Mean & Range \\
\hline Age $(n=123)$ & 34.07 & $19-64$ \\
\hline Years married to spouse $(n=104)$ & 7.33 & $1-40$ \\
\hline Age started smoking $(n=136)$ & 18.49 & $8-35$ \\
\hline Years of smoking $(n=139)$ & 14.24 & $1-43$ \\
\hline Cigarettes smoked each day $(n=147)$ & 16.14 & $1-60$ \\
\hline FTND* $^{*}(n=162)$ & 4.63 & $0-10$ \\
\hline \multirow{2}{*}{$\begin{array}{l}\text { Number of quit attempts in past year } \\
(n=62)\end{array}$} & 5.27 & $0-60$ \\
\hline & Frequency & Percent \\
\hline \multicolumn{3}{|l|}{$\operatorname{Sex}(n=123)$} \\
\hline Male & 53 & 43.09 \\
\hline Female & 70 & 56.91 \\
\hline \multicolumn{3}{|l|}{ Race $(n=119)$} \\
\hline White & 94 & 78.99 \\
\hline Black & 16 & 13.45 \\
\hline Others & 9 & 7.56 \\
\hline \multicolumn{3}{|l|}{ Highest level of education $(n=115)$} \\
\hline High school or less & 32 & 27.83 \\
\hline College or more & 83 & 72.17 \\
\hline \multicolumn{3}{|l|}{ Employment status $(n=120)$} \\
\hline Employed & 85 & 70.83 \\
\hline Unemployed & 30 & 25.00 \\
\hline Retired & 5 & 4.17 \\
\hline \multicolumn{3}{|l|}{ Comorbidities $(n=104)$} \\
\hline Cancer & 9 & 7.96 \\
\hline Lung disease & 23 & 20.18 \\
\hline Heart disease & 15 & 12.93 \\
\hline High blood pressure & 18 & 15.25 \\
\hline Psychiatric problems & 35 & 30.70 \\
\hline Substance abuse & 16 & 13.79 \\
\hline Diabetes & 12 & 10.43 \\
\hline $\begin{array}{l}\text { High nicotine dependence level } \\
\left.\text { (FTND }{ }^{*} \geq 6\right)(n=162)\end{array}$ & 62 & 38.3 \\
\hline \multicolumn{3}{|l|}{ Thinking of quitting $(n=158)$} \\
\hline Within the next 30 days & 44 & 27.85 \\
\hline Within the next 6 months & 58 & 36.71 \\
\hline Not thinking of quitting & 56 & 35.44 \\
\hline $\begin{array}{l}\text { Tried to quit individually in past year } \\
\text { (at least } 24 \mathrm{hr} \text { ) }(n=158)\end{array}$ & 73 & 46.20 \\
\hline $\begin{array}{l}\text { Tried to quit jointly in past year (at } \\
\text { least } 24 \mathrm{hr} \text { ) }(n=138)\end{array}$ & 46 & 33.30 \\
\hline \multicolumn{3}{|c|}{ Methods to assist with smoking cessation $(n=101)$} \\
\hline Quit on own & 75 & 40.98 \\
\hline Pharmacotherapy & 28 & 15.30 \\
\hline Buddy system & 25 & 13.66 \\
\hline Other & 43 & 25.1 \\
\hline
\end{tabular}

(Continues)
TABLE 1 (Continued)

\begin{tabular}{|c|c|c|}
\hline & Mean & Range \\
\hline \multicolumn{3}{|c|}{ Prompted you to begin smoking again $(n=97)$} \\
\hline Chronic stress & 46 & 25.14 \\
\hline $\begin{array}{l}\text { Crisis (Death, illness, loss of job, } \\
\text { family issues) }\end{array}$ & 35 & 19.13 \\
\hline Social/party situations & 33 & 18.03 \\
\hline Withdrawal symptoms & 33 & 18.03 \\
\hline Boredom & 21 & 11.48 \\
\hline Others & 13 & 7.10 \\
\hline $\begin{array}{l}\text { Used other tobacco products } \\
(n=160)\end{array}$ & 37 & 23.10 \\
\hline \multicolumn{3}{|c|}{ Types of other tobacco products $(n=37)$} \\
\hline Cigars & 22 & 12.02 \\
\hline Pipes of tobacco & 15 & 8.20 \\
\hline Cigarillos & 17 & 9.29 \\
\hline Snuff/Chewing Tobacco & 9 & 4.92 \\
\hline E-cigarette & 1 & 0.55 \\
\hline
\end{tabular}

Abbeviations: FTND, Fagerstrom test of nicotine dependence.

the averages of daily cigarette consumption (vs. 16 cigarettes/ day in the general population) and age of smoking initiation (vs. 17.9 years in the general population) are similar to the general population, more dual-smoker couples appear to start smoking early (CDC, n.d.). About $11 \%$ of dual-smokers started smoking before age of 13 years (vs. 7.3\% in the American population), which is associated with increased risks for smoking-related morbidity and mortality (Choi \& Stommel 2017; Lipkus et al., 2013). Indeed, the study participants reported a high prevalence of smoking-related diseases, such as lung diseases, high blood pressure, and heart diseases, which was surprising given their relatively young age. Such findings confirmed dual-smoker couples are at higher risks for smoking-related morbidity and mortality, indicating health disparities among this population (Lipkus et al., 2013).

The majority of dual-smoker couples allowed smoking at home. Furthermore, the more time they shared smoking with their spouses, the fewer smoking bans they implemented at home. Smoking bans at home are considered social pressure against smoking. Home smoking bans not only protect non-smoking family members from second-hand smoking, but also encourage smokers to quit smoking (Zablocki et al., 2014). Smoking cessation interventions should include home smoking policies, which would increase motivation/ intention to quit, increase quit attempts, and lower smoking lapse/ relapse (Gilpin et al., 1999; Zablocki et al., 2014).

Fortunately, dual-smoker couples reported high levels of motivation to quit smoking. Couples sharing more smoking time appeared to be more motivated compared to couples sharing less smoking time. Despite their high levels of motivation, dual-smoker couples showed low success rates in quitting (Christakis \& Fowler, 2008; Dollar et al., 2009; Hawkins et al., 2010; Lee \& Kahende, 2007; 
TABLE 2 Social contexts associated with smoking

\begin{tabular}{|c|c|c|}
\hline & Mean & Range \\
\hline $\begin{array}{l}\text { Cigarettes the spouse smoked each } \\
\text { day }(n=118)\end{array}$ & 16.88 & $2-50$ \\
\hline \multirow{2}{*}{$\begin{array}{l}\text { Number of joint quit attempts in past } \\
\text { year }(n=138)\end{array}$} & 1.48 & $0-30$ \\
\hline & Frequency & Percent \\
\hline \multicolumn{3}{|l|}{ Smoking with spouse $(n=128)$} \\
\hline$<50 \%$ of smoking time & 56 & 43.75 \\
\hline$\geq 50 \%$ of smoking time & 72 & 56.25 \\
\hline \multicolumn{3}{|l|}{ Smoking banned at home $(n=139)$} \\
\hline Always allowed at home & 79 & 56.83 \\
\hline $\begin{array}{l}\text { Allowed sometimes or in some } \\
\text { places }\end{array}$ & 50 & 35.97 \\
\hline Never allowed & 10 & 7.19 \\
\hline \multicolumn{3}{|c|}{ Motivation for joint quit attempt(s) $(n=181)$} \\
\hline Health concerns & 18 & 41.86 \\
\hline Cost/money & 7 & 16.28 \\
\hline Children/pregnancy & 5 & 11.63 \\
\hline Others & 13 & 30.23 \\
\hline \multicolumn{3}{|c|}{ How much do you want your spouse to help you quit $(n=124)$} \\
\hline Much/A great deal & 57 & 42.22 \\
\hline Somewhat & 40 & 29.63 \\
\hline Not at all/Little & 38 & 28.15 \\
\hline \multicolumn{3}{|c|}{ Success if spouse helped them quit $(n=125)$} \\
\hline Likely/extremely likely & 67 & 49.30 \\
\hline Neutral & 48 & 35.30 \\
\hline Unlikely/Extremely unlikely & 21 & 15.40 \\
\hline $\begin{array}{l}\text { Interested in smoking cessation } \\
\text { services for dual -smoker couples } \\
(n=151)\end{array}$ & 96 & 63.58 \\
\hline \multicolumn{3}{|c|}{ Preferred smoking cessation interventions ( $n=79)$} \\
\hline $\begin{array}{l}\text { Face to face cessation counseling } \\
\text { from health professionals }\end{array}$ & 19 & 10.38 \\
\hline $\begin{array}{l}\text { Telephone counseling from health } \\
\text { professionals }\end{array}$ & 32 & 17.49 \\
\hline $\begin{array}{l}\text { Meeting with support groups } \\
\text { (Buddy system) }\end{array}$ & 22 & 12.02 \\
\hline Take home workbook and/or video & 35 & 19.13 \\
\hline Pharmacotherapy & 42 & 22.95 \\
\hline Website to help you quit smoking & 44 & 24.04 \\
\hline $\begin{array}{l}\text { Mobile cessation application for } \\
\text { smoking cessation }\end{array}$ & 35 & 19.13 \\
\hline
\end{tabular}

Manchón Walsh et al., 2007). This may be because $41.0 \%$ quit on their own and only $15.3 \%$ utilized resources for smoking cessation. The reason why they do not use any professional help or resources is not clear, but could be a reflection of lack of available resources for them. Studies show that minorities have fewer opportunities to receive cessation interventions (Browning, Ferketich, Salsberry, \& Wewers, 2008) and are thus less likely to utilize resources (Trinidad,
Pérez-Stable, White, Emery, \& Messer, 2011). Such findings demonstrate a need for innovative and tailored cessation interventions for dual-smoker couples. Public health nurses are in the best position to assess dual-smokers' needs for smoking cessation and provide support and resources given their counseling skills and broad knowledge of health promotion and prevention.

Our study findings suggest several implications for public health nurses to develop cessation interventions tailored to dual-smoker couples. Firstly, smoking cessation interventions should address smoking-related social contexts, such as home smoking bans and shared smoking time. Interventions with strategies to implement home smoking bans and to encourage participants to engage in other activities not related to smoking would prevent couples from viewing cessation as a threat to their relationship. Moreover, consistent with a previous study (Siahpush \& Carlin, 2006), health concerns motivated the couples to make quit attempts, whereas chronic stress and personal crisis were the top reasons for relapses. Therefore, interventions should emphasize the health effects of dual-smoker couples and include stress management strategies.

Secondly, the findings that more couples made more individual quit attempts than joint attempts (46.20\% vs. $33.30 \%$ ) suggest couples appeared to experience more difficulties with joint quit attempts. It is not clear why they had more difficulties with joint quit attempts. This may be related to unmet spousal support for smoking cessation. As shown in another study as well (Ranby, Lewis, Toll, Rohrbaugh, \& Lipkus, 2012), dual-smoker couples expressed a strong desire for their spouse's support when trying to quit. Unmet spousal support might result in relationship dissatisfaction, which then lead to fewer joint quit attempts. Communal coping (viewing smoking as "ours" rather than "yours" or "mine") and cooperative, reinforced messages from spouses have shown to improve intent to quit smoking, confidence to quit, and actual success (Caponnetto \& Polosa, 2008; Dollar et al., 2009; Mermelstein, Cohen, Lichtenstein, Baer, \& Kamarck, 1986). Therefore, cessation interventions for dual-smoker couples should encourage both members to make joint quit attempts, support each other, and increase communal coping (Caponnetto \& Polosa, 2008; Dollar et al., 2009; Mermelstein et al., 1986).

While making joint quit attempts is more challenging, it has been recommended that interventions and clinical guidelines should consider targeting both members rather than only one and treat couples as a treatment unit (Cobb et al., 2014; Shoham et al., 2006). Otherwise, interventions involving only one member would have limited efficacy (Christakis \& Fowler, 2008; Dollar et al., 2009; Falba \& Sindelar, 2008; Homish \& Leonard, 2005) as the individual would be exposed to smoking cues on a daily basis in his/her environment. If one member has a lapse/relapse, interventions should create a safe space for each member to change independently off the other (Rohrbaugh et al., 2001). Such smoking cessation programs tailored to dual-smoker couples have the potential to reduce health disparities and decrease premature deaths related to smoking, which have been burdensome nationally and globally (Allender, Balakrishnan, 
TABLE 3 Differences in social contexts based on shared smoking time

\begin{tabular}{|c|c|c|c|}
\hline & $\begin{array}{l}\text { Smoking with spouse }<50 \% \text { of } \\
\text { smoking time, } n(\%)\end{array}$ & $\begin{array}{l}\text { Smoking with spouse } \geq 50 \% \\
\text { of smoking time, } n(\%)\end{array}$ & $p$ \\
\hline \multicolumn{4}{|l|}{ Motivation to quit $(n=127)$} \\
\hline Yes, within the next 6 months & $23(41.82)$ & $26(36.11)$ & \multirow{2}{*}{.002} \\
\hline No, I am not thinking of quitting & $26(47.27)$ & 19 (26.39) & \\
\hline \multicolumn{4}{|l|}{ Smoking bans at home $(n=127)$} \\
\hline Smoking is always allowed at home & $23(41.82)$ & $51(70.83)$ & \multirow[t]{3}{*}{.000} \\
\hline Smoking is allowed only sometimes or in some places & $30(54.55)$ & $15(20.83)$ & \\
\hline Smoking is never allowed & $2(3.64)$ & $6(8.33)$ & \\
\hline \multicolumn{4}{|l|}{ Success if spouse help quit $(n=125)$} \\
\hline Likely/extremely likely & $21(38.18)$ & $42(60.00)$ & .015 \\
\hline Neutral/unlikely/extremely unlikely & $34(61.82)$ & $28(40.00)$ & \\
\hline $\begin{array}{l}\text { Interested in smoking cessation intervention for dual-smoker } \\
\text { couples }(n=128)\end{array}$ & $24(42.86)$ & $61(84.72)$ & $<.0001$ \\
\hline
\end{tabular}

Scarborough, Webster, \& Rayner, 2009; Kahende, Woollery, \& Lee, 2007).

Lastly, given their preference for technology-based cessation interventions, web-based or mobile phone-based interventions, both of which were effective across various populations (Myung, McDonnell, Kazinets, Seo, \& Moskowitz, 2009; Whittaker, McRobbie, Bullen, \& Rodgers, 2016), would better assist this population. Technology-based cessation interventions have unique advantages, such as broad reach at low costs, ability to interact between researchers and participants, and easy tailoring to individuals (Ghorai, Akter, Khatun, \& Ray, 2014; Smith, 2015). However, no web-based or mobile phone-based interventions are tailored to dual-smoker couples yet.

There are several limitations to consider. Self-reporting and recall bias may exist as the data were collected based on participants' ability to remember, particularly when recall periods are long (Jupp, 2006). All data were based on reports from only one member of a dual-smoker couple. Reports from one member can be biased, especially when the sample is not balanced in sex (Lewis et al., 2006; Rohrbaugh, Shoham, \& Dempsey, 2009). However, given our sample was balanced between male and female participant, it is unlikely this bias was introduced. Future studies including both members of dual-smoker couples will be needed to verify the study findings. Missing data may also result in biased findings (Westreich, 2012). However, additional analysis-Little's MCAR (Missing Completely at Random) test-showed that the data were missing completely at random $\left(\chi^{2}=625.585, d f=592, p=.164\right)$. Thus, the influence of missing data on analysis should be minimal. Study findings may be also biased due to the study design (online survey study) and the study sample. Our study sample may be composed of more participants who were tech-savvy given the online-survey study design, thus some of the findings, such as preference of technology-based cessation interventions, can be unique to this sample. Therefore, the study findings may not be generalizable to non-tech-savvy populations. Additionally, the survey did not include questions about sexual identity and gender of spouse, thus, we were not able to compare patterns of smoking between same sex and different sex couples (Gamarel et al., 2016).

\section{5 | CONCLUSIONS}

Dual-smoker couples showed interdependence and spousal concordance of smoking patterns. They reported more difficulties with joint quit attempts than individual quit attempts, albeit they had high levels of motivation to quit, and preferred technology-based interventions. Such findings provide implications for smoking cessation interventions tailored to dual-smoker couples. Technology-based cessation interventions addressing smoking bans, spousal support, and stress and health concerns may reduce health disparities and prevent premature deaths among dualsmoker couples.

\section{ORCID}

Seung Hee Choi (iD https://orcid.org/0000-0003-4695-5462 


\section{REFERENCES}

Allender, S., Balakrishnan, R., Scarborough, P., Webster, P., \& Rayner, M. (2009). The burden of smoking-related ill health in the UK. Tobacco Control, 18(4), 262-267. https://doi.org/10.1136/ tc. 2008.026294

Boyd, S. M., Ranby, K. W., MacKillop, J., \& Lipkus, I. M. (2016). Willingness to provide support for a quit attempt: A study of partners of smokers. Journal of Health Psychology, 21(9):1840-1849. https://doi. org/10.1177/1359105314567209. Epub 2015 Jan 20.

Browning, K. K., Ferketich, A. K., Salsberry, P. J., \& Wewers, M. E. (2008). Socioeconomic disparity in provider-delivered assistance to quit smoking. Nicotine \& Tobacco Research, 10(1), 55-61. https://doi. org/10.1080/14622200701704905

Caponnetto, P., \& Polosa, R. (2008). Common predictors of smoking cessation in clinical practice. Respiratory Medicine, 102(8), 1182-1192. https://doi.org/10.1016/j.rmed.2008.02.017

CDC (n.d.). Current cigarette smoking among U.S. adults aged 18 years and older. Retrieved from https://www.cdc.gov/tobacco/campaign/ tips/resources/data/cigarette-smoking-in-united-states.html

Choi, S. H., Mitchell, J., \& Lipkus, I. (2017). Lessons learned from an online study with dual-smoker couples. American Journal of Health Behavior, 41(1), 61-66. https://doi.org/10.5993/AJHB.41.1.6

Choi, S. H., Pohl, J. M., Terrell, J. E., Redman, R. W., \& Duffy, S. A. (2013). Factors associated with smoking among operating engineers. Workplace Health \& Safety, 61(9), 385-392. https://doi. org/10.3928/21650799-20130816-67

Choi, S. H., \& Stommel, M. (2017). Impact of age at smoking initiation on smoking-related morbidity and all-cause mortality. American Journal of Preventive Medicine, 53(1), 33-41. https://doi.org/10.1016/j. amepre.2016.12.009

Christakis, N. A., \& Fowler, J. H. (2008). The collective dynamics of smoking in a large social network. The New England Journal of Medicine, 358(21), 2249-2258. https://doi.org/10.1056/NEJMsa0706154

Cobb, L. K., McAdams-DeMarco, M. A., Huxley, R. R., Woodward, M., Koton, S., Coresh, J., \& Anderson, C. A. M. (2014). The association of spousal smoking status with the ability to quit smoking: The atherosclerosis risk in communities study. American Journal of Epidemiology, 179(10), 1182-1187. https://doi.org/10.1093/aje/kwu041

Cohen, J. (1988). Statistical power analysis for the behavioral sciences. Hillsdale, NJ: L. Erlbaum Associates.

Dillman, D. A., Smyth, J. D., \& Christian, L. M. (2014). Internet, phone, mail, and mixed-model surveys: The tailored design method (4th ed). New Jersey: Wiley.

Dollar, K. M., Homish, G. G., Kozlowski, L. T., \& Leonard, K. E. (2009) Spousal and alcohol-related predictors of smoking cessation: A longitudinal study in a community sample of married couples. American Journal of Public Health, 99(2), 231-233. https://doi.org/10.2105/ AJPH.2008.140459

Fagerstrom, K. O., Kunze, M., Schoberberger, R., Breslau, N., Hughes, J. R., Hurt, R. D., ... Zatonski, W. (1996). Nicotine dependence versus smoking prevalence: Comparisons among countries and categories of smokers. Tobacco Control, 5(1), 52-56. https://doi.org/10.1136/ tc. 5.1 .52

Falba, T. A., \& Sindelar, J. L. (2008). Spousal concordance in health behavior change. Health Services Research, 43(1p1), 96-116. https://doi. org/10.1111/j.1475-6773.2007.00754.x

Gallup (n.d., March 13, 2014). In U.S., Smoking Rate Lowest in Utah, Highest in Kentucky. Retrieved from https://www.gallup.com/ poll/167771/smoking-rate-lowest-utah-highest-kentucky.aspx

Gamarel, K. E., Kahler, C. W., Lee, J. H., Reisner, S. L., Mereish, E. H., Matthews, A. K., \& Operario, D. (2016). Sexual orientation disparities in smoking vary by sex and household smoking among US adults: Findings from the 2003-2012 National Health and Nutrition Examination Surveys. Preventive Medicine, 82, 1-6. https://doi. org/10.1016/j.ypmed.2015.10.008
Ghorai, K., Akter, S., Khatun, F., \& Ray, P. (2014). mHealth for smoking cessation programs: A systematic review. Journal of Personalized Medicine, 4(3), 412-423. https://doi.org/10.3390/jpm4030412

Gilpin, E., White, M., Farkas, A., \& Pierce, J. P. (1999). Home smoking restrictions: Which smokers have them and how they are associated with smoking behavior. Nicotine \& Tobacco Research, 1(2), 153-162. https://doi.org/10.1080/14622299050011261

Hawkins, J., Hollingworth, W., \& Campbell, R. (2010). Long-term smoking relapse: A study using the British household panel survey. Nicotine \& Tobacco Research, 12(12), 1228-1235. https://doi.org/10.1093/ntr/ ntq175

Heatherton, T. F., Kozlowski, L. T., Frecker, R. C., \& Fagerstrom, K.-O. (1991). The Fagerström test for nicotine dependence: A revision of the Fagerstrom tolerance questionnaire. British Journal of Addiction, 86(9), 1119-1127. https://doi.org/10.1111/j.1360-0443.1991.tb018 79.x

Homish, G. G., Eiden, R. D., Leonard, K. E., \& Kozlowski, L. T. (2012). Social-environmental factors related to prenatal smoking. Addictive Behaviors, 37(1), 73-77. https://doi.org/10.1016/j. addbeh.2011.09.001

Homish, G. G., \& Leonard, K. E. (2005). Spousal influence on smoking behaviors in a US community sample of newly married couples. Social Science and Medicine, 61(12), 2557-2567. https://doi.org/10.1016/j. socscimed.2005.05.005

Jackson, S. E., Steptoe, A., \& Wardle, J. (2015). The influence of partner's behavior on health behavior change: The english longitudinal study of ageing. JAMA Internal Medicine, 175(3), 385-392. https://doi. org/10.1001/jamainternmed.2014.7554

Jupp, V. (2006). The SAGE dictionary of social research methods. London: SAGE Publications Ltd.

Kahende, J. W., Woollery, T. A., \& Lee, C.-W. (2007). Assessing medical expenditures on 4 smoking-related diseases, 1996-2001. American Journal of Health Behavior, 31(6), 602. https://doi.org/10.5993/ AJHB.31.6.5

Kendrick, J. S., Zahniser, S. C., Miller, N., Salas, N., Stine, J., Gargiullo, P. M., ... Metzger, R. W. (1995). Integrating smoking cessation into routine public prenatal care: The Smoking Cessation in Pregnancy project. American Journal of Public Health, 85(2), 217-222. https://doi. org/10.2105/AJPH.85.2.217

Lee, C.-W., \& Kahende, J. (2007). Factors Associated With Successful Smoking Cessation in the United States, 2000. American Journal of Public Health, 97(8), 1503-1509. https://doi.org/10.2105/ AJPH.2005.083527

Lewis, M. A., McBride, C. M., Pollak, K. I., Puleo, E., Butterfield, R. M., \& Emmons, K. M. (2006). Understanding health behavior change among couples: An interdependence and communal coping approach. Social Science and Medicine, 62(6), 1369-1380. https://doi.org/10.1016/j. socscimed.2005.08.006

Lipkus, I. M., Ranby, K. W., Lewis, M. A., \& Toll, B. (2013). Reactions to framing of cessation messages: insights from dual-smoker couples. Nicotine \& Tobacco Research, 15(12), 2022-2028. https://doi. org/10.1093/ntr/ntt091

Manchón Walsh, P., Carrillo, P., Flores, G., Masuet, C., Morchon, S., \& Ramon, J. M. (2007). Effects of partner smoking status and gender on long term abstinence rates of patients receiving smoking cessation treatment. Addictive Behaviors, 32(1), 128-136. https://doi. org/10.1016/j.addbeh.2006.03.027

Mermelstein, R., Cohen, S., Lichtenstein, E., Baer, J. S., \& Kamarck, T. (1986). Social support and smoking cessation and maintenance. Journal of Consulting and Clinical Psychology, 54(4), 447. https://doi. org/10.1037/0022-006X.54.4.447

Mukerji, S. S., Duffy, S. A., Fowler, K. E., Khan, M., Ronis, D. L., \& Terrell, J. E. (2007). Comorbidities in head and neck cancer: Agreement between self-report and chart review. Otolaryngology - Head and Neck Surgery, 136(4), 536-542. https://doi.org/10.1016/j.otohns.2006.10.041 
Myung, S., McDonnell, D. D., Kazinets, G., Seo, H., \& Moskowitz, J. M. (2009). Effects of web- and computer-based smoking cessation programs: Meta-analysis of randomized controlled trials. Archives of Internal Medicine, 169(10), 929-937. https://doi.org/10.1001/archi nternmed.2009.109

Park, E. R., Chang, Y., Quinn, V. P., Ross, K., \& Rigotti, N. A. (2009). Perceived support to stay quit: What happens after delivery? Addictive Behaviors, 34(12), 1000-1004. https://doi.org/10.1016/j. addbeh.2009.06.005

Prochaska, J. O., Velicer, W. F., Fava, J. L., Rossi, J. S., \& Tsoh, J. Y. (2001). Evaluating a population-based recruitment approach and a stage-based expert system intervention for smoking cessation. Addictive Behaviors, 26(4), 583-602. https://doi.org/10.1016/ S0306-4603(00)00151-9

Ranby, K. W., Lewis, M. A., Toll, B. A., Rohrbaugh, M. J., \& Lipkus, I. M. (2012). Perceived risk and worry for one's partner and self correlate with desire to quit in dual-smoker couples. Cancer Epidemiology, Biomarkers and Prevention, 21(3), 561-561. https://doi. org/10.1158/1055-9965.EPI-12-0080

Rohrbaugh, M. J., Shoham, V., \& Dempsey, C. L. (2009). Gender differences in quit support by partners of health-compromised smokers. Journal of Drug Issues, 39(2), 329-346. https://doi.org/10.1177/0022042609 03900206

Rohrbaugh, M. J., Shoham, V., Skoyen, J.A., Jensen, M., \& Mehl, M. R. (2012). We-talk, communal coping, and cessation success in a couple-focused intervention for health-compromised smokers. Family Process, 51(1), 107-121. https://doi.org/10.1111/j.1545-5300.2012.01388.x

Rohrbaugh, M. J., Shoham, V., Trost, S., Muramoto, M., Cate, R. M., \& Leischow, S. (2001). Couple dynamics of change-resistant smoking: Toward a family consultation model. Family Process, 40(1), 15-31. https://doi.org/10.1111/j.1545-5300.2001.4010100015.x

Severson, H. H., Andrews, J. A., Lichtenstein, E., Wall, M., \& Zoref, L. (1995). Predictors of smoking during and after pregnancy: A survey of mothers of newborns. Preventive Medicine, 24(1), 23-28. https:// doi.org/10.1006/pmed.1995.1004

Shoham, V., Rohrbaugh, M. J., Trost, S. E., \& Muramoto, M. (2006). A family consultation intervention for health-compromised smokers. Journal of Substance Abuse Treatment, 31(4), 395-402. https://doi. org/10.1016/j.jsat.2006.05.012

Siahpush, M., \& Carlin, J. B. (2006). Financial stress, smoking cessation and relapse: Results from a prospective study of an
Australian national sample. Addiction, 101(1), 121-127. https://doi. org/10.1111/j.1360-0443.2005.01292.x

Smith, A. (2015). U.S. Smartphone Use in 2015. Retrieved from https ://www.pewinternet.org/2015/04/01/us-smartphone-use-in-2015/

Tidey, J. W., \& Rohsenow, D. J. (2009). Smoking expectancies and intention to quit in smokers with schizophrenia, schizoaffective disorder and non-psychiatric controls. Schizophrenia Research, 115(2), 310-316. https://doi.org/10.1016/j.schres.2009.09.032

Trinidad, D. R., Pérez-Stable, E. J., White, M. M., Emery, S. L., \& Messer, K. (2011). A nationwide analysis of US racial/ethnic disparities in smoking behaviors, smoking cessation, and cessation-related factors. American Journal of Public Health, 101(4), 699-706. https://doi. org/10.2105/AJPH.2010.191668

van Dellen, M. R., Boyd, S. M., Ranby, K. W., MacKillop, J., \& Lipkus, I. M. (2015). Willingness to provide support for a quit attempt: A study of partners of smokers. Journal of Health Psychology, 21(9), 1840-1849. https://doi.org/10.1177/1359105314567209

Venters, M. H., Jacobs, J. D. R., Luepker, R. V., Maiman, L. A., \& Gillum, R. F. (1984). Spouse concordance of smoking patterns: The Minnesota Heart Survey. American Journal of Epidemiology, 120(4), 608-616. https://doi.org/10.1093/oxfordjournals.aje.a113922

Westreich, D. (2012). Berkson's bias, selection bias, and missing data. Epidemiology, 23(1), 159-164. https://doi.org/10.1097/EDE.0b013 e31823b6296

Whittaker, R., McRobbie, H., Bullen, C., Rodgers, A., \& Gu, Y. (2016). Mobile phone-based interventions for smoking cessation. Cochrane Database of Systematic Reviews, 4, CD006611.https://doi. org/10.1002/14651858.CD006611.pub4

Zablocki, R. W., Edland, S. D., Myers, M. G., Strong, D. R., Hofstetter, C. R., \& Al-Delaimy, W. K. (2014). Smoking ban policies and their influence on smoking behaviors among current California smokers: A population-based study. Preventive Medicine, 59, 73-78. https://doi. org/10.1016/j.ypmed.2013.11.018

How to cite this article: Choi SH, Ling J, Noonan D, Kim W. Smoking behavior and social contexts associated with smoking among dual-smoker couples. Public Health Nurs. 2020;37:161-168. https://doi.org/10.1111/phn.12686 